Cytogenet Genome Res 1970;9:160

\title{
Important notice to contributors
}

Dr. Orlando J. Miller will serve as Acting Editor oî Cytogenet Genome Res during Dr. Klinger's sabbatical leave.

All manuscripts, proof and correspondence intended to reach the Editorial Office after

1 May, 1970

should be addressed as follows:

Orlando J. Miller, M. D.

Department of Human Genetics and Development

College of Physicians and Surgeons

630 West 168th Street

New York, NY 10032 (USA) 